\title{
Do Citizens Know Whether Their State Has Decriminalized Marijuana? Assessing the Perceptual Component of Deterrence Theory*
}

\author{
ROBERT MACCOUN \\ University of California at Berkeley \\ ROSALIE LICCARDO PACULA \\ RAND Corporation and NBER \\ JAMIE CHRIQUI \\ University of Illinois at Chicago \\ KATHERINE HARRIS \\ RAND Corporation \\ PETER REUTER \\ University of Maryland - College Park and RAND
}

Deterrence theory proposes that legal compliance is influenced by the anticipated risk of legal sanctions. This implies that changes in law will produce corresponding changes in behavior, but the marijuana decriminalization literature finds only fragmentary suppont for this prediction. But few studies bave directly assessed the accuracy of citizens' perceptions of legal sanctions. The heterogeneity in state statutory penalties for marijuana possession across the United States provides an opportunity to examine this issue. Using national sumey data, we find that the percentages who believe they could be jailed for marijuana possession are quite similar in both states that bave removed those penalties and those that have not. Our results belp to clarify why statistical studies bave found inconsistent support for an effect of decriminalization on marijuana possession.

\section{INTRODUCTION}

The primary reason for prohibiting marijuana use (and possession) is the presumption that such a policy deters individuals from using marijuana. According to criminal deterrence theory, the prevalence of marijuana use should be influenced by the swiftness, severity and certainty of punishment (see

\footnotetext{
* The authors are grateful to Justin McCrary, Erin Murphy, Eric Talley, and the anonymous reviewers for helpful comments. Research presented here was funded by a grant from the Robert Wood Johnston Foundation's SAPRP program. Katherine Harris worked in the Office of Applied Studies at Substance Abuse and Mental Health Services Administration (SAMHSA) when we conducted our analyses, which is how we gained access to these restricted National Surveys on Drug Use and Health (NSDUH) data.
} 
reviews by Kessler and Levitt, 1999; Nagin, 1998; Patemoster, 1987). Ceteris paribus, reductions in the statutory penalties for using marijuana should weaken the deterrent effect of the prohibition and increase drug use. But this prediction hinges on three important assumptions (MacCoun, 1993). First, it assumes that the change in statutory policy accurately reflects a real change in how the policy is implemented. Second, it assumes that there are no offsetting changes in enforcement that occur simultaneously with the change in law. Third, it assumes the public is aware and cognizant of the change in statutory penalties and hence incorporates this new information into their behavior.

In the 1970 s about 12 states "decriminalized" marijuana possession. As commonly interpreted (though see discussion below) this meant that an individual who was caught by the police in possession of a small amount of marijuana would no longer be subject to a potential term of incarceration but would receive only a civil penalty, presumably seen as less serious. Although a large research base exists examining the effects on marijuana use of marijuana decriminalization in the United States, substantially less work has been done examining the three underlying assumptions that are necessary in order to properly interpret the effects found when examining the statutory change. In particular, only one study has examined whether the public was even aware of the change in law, and this study examined knowledge of high school seniors not the entire population (Johnston et al., 1981).

This paper begins to fill the void by providing new evidence of the public's knowledge of their state's statutory maximum penalties for marijuana possession, using a nationally representative sample of individuals 18 years and older. We have framed our analysis with respect to two literatures: drug decriminalization and deterrence theory. But it is important to emphasize at the outset that our analyses do not directly test either deterrence theory or the effects of decriminalization on drug use. Rather, the distinctive contribution of our study is to shed light on one key assumption underlying marijuana prohibition specifically and deterrence theory more generally: Are actual differences in maximum statutory penalties reflected in ordinary citizens' perceptions of their laws?

\subsection{THE EXISTING LITERATURE}

The appropriate legal response to marijuana possession has been a matter of public debate in the U.S. and Western Europe since the 1970s, and in Canada and Australia more recently (MacCoun and Reuter, 2001; Pacula et al., 2005). The debate has many dimensions, and only some are empirical (MacCoun et al., 1993). But the core empirical question - does decriminalization increase marijuana use? -- has been surprisingly difficult to resolve. Elsewhere (Hall and Pacula, 2003; 
MacCoun and Reuter, 2001; Pacula et a.,, 2005), we review in some detail the decriminalization experiences of the United States, Australia, the Netherlands, and other countries. ${ }^{1}$ Here we briefly summarize that literature.

Early U.S. studies generally found that decriminalization had no statistically significant impact on use in the United States. These studies focused on the years immediately following the passage of decriminalization statutes in eleven states. The most ambitious analysis found no significant association with use in both cross-sectional and longitudinal comparisons, using micro-level data from the late 1970s Monitoring the Future Survey of High School Seniors (Johnston et al., 1981). Other state-specific analyses found similar null results (see Single, 1989).

Studies examining the early years of decriminalization in several Australian jurisdictions also failed to find an effect on prevalence in simple cross-sectional and longitudinal comparisons (Donnelly et al., 1995; McGeorge and Aitken, 1997). Drawing on a sparse set of cross-sectional and longitudinal indicators, MacCoun and Reuter $(1997,2001)$ argued that Dutch decriminalization in the 1970s had no measurable impact on levels of use over the first decade, though they tentatively attributed a later increase in prevalence to the rapid expansion of the number of commercial retail coffeeshop outlets for cannabis.

Only one study has suggested an effect of state decriminalization during the 1970s. Model (1993) analyzed the effect of marijuana decriminalization on drug mentions in hospital emergency room episodes using data from the 1975-1978 Drug Abuse Warning Network (DAWN). Her analyses showed that cities in states that had decriminalized marijuana experienced higher marijuana ER mentions and lower other drug mentions than non-decriminalized cities. Model did not estimate a demand function directly, but her results implied that under decriminalization, drug users might have substituted marijuana for hard drugs.

More recent statistical analysis have generated mixed findings, with some studies showing no effect while others showed a positive and statistically significant effect. For example, DiNardo and Lemieux (2001) found no effects of state marijuana decriminalization using state-level aggregated data from the 19801989 Monitoring the Future Survey. They estimated log-linear and bivariate probit models of the likelihood of using alcohol and marijuana, so unlike previous models, their model considered the possible relationship between alcohol and marijuana use. Thies and Register (1993) found no significant impact of decriminalization in their analysis of data on young adults from the 1984 and 1988 National Longitudinal Survey of Youth (NLSY). They estimated logit and tobit specifications of the demand for marijuana, binge drinking, and cocaine and included cross-price effects in all of the regressions. Finally, Pacula (1998) found

1 This section draws on material in Pacula et al. (2005).

DOI: $10.2202 / 1555-5879.1227$ 
no significant effect of decriminalization policy in her two-part model specification of the demand for marijuana using data from just the 1984 NLSY. Her model differed from that of Thies and Register in that it included additional proxies for the price of marijuana and other substances.

Saffer and Chaloupka (1999) also found a significant decriminalization effect in individual level prevalence equations for past year and past month use of marijuana, alcohol, cocaine, and heroin using data from the 1988, 1990, and 1991 National Household Survey on Drug Abuse. Unlike other analyses, Saffer and Chaloupka's work controlled for various measures of the monetary price of legal and illicit drugs in addition to controlling for whether a state had a formalized decriminalization policy. Additional analyses finding evidence of a statistically positive association in nationally representative samples of youth and young adults in the United States include Williams et al. (2004), DeSimone and Farrelly (2003) and Pacula et al. (2003).

\subsection{WHAT EXPLAINS THE DISCREPANCIES?}

The inconsistencies in these results may reflect statistically or methodological artifacts. The correlational nature of the analyses does not permit rigorous causal identification, and the statistical models presented by past authors vary in many respects. But putting aside the very real possibility of statistical or methodological artifacts, we see at least two possible substantive explanations.

One is that the effect of law varies by age. Cameron and Williams (2001) find in their analysis of Australian cannabis use that the impact of legal sanctions varies substantially across people depending on the age of the population being examined. Youth in their study were less likely to be influenced by legal sanctions while behavior among young adults was statistically influenced by these policies. Studies finding a policy effect have examined adult populations (Model, 1993; Saffer and Chaloupka, 1999); studies finding no effect have tended to focus on youth or young adults (DiNardo and Lemieux, 2001; Johnston et al., 1981; Pacula, 1998; Thies and Register, 1993). It is tempting to conclude that youths are less sensitive to marijuana arrest risks due to lower levels of risk aversion and/or greater impulsivity. But Reyda and Farley (2006) review evidence that "(a) despite conventional wisdom, adolescents do not perceive themselves to be invulnerable, and perceived vulnerability declines with increasing age; (b) ...adolescents typically overestimate important risks... and (c) some biases in judgment and decision making grow with age."

Another possibility is that the period in which the policies were evaluated may matter. This inconsistency in years evaluated may be generating differences due to cohort effects or unidentified policy changes that are not captured fully in the analysis. Cohort effects are likely to exist due to the fact that public awareness of 
specific policies generally declines over time as we move farther away from the period in which the policy was discussed or adopted. There are a number of other unidentified policy changes that could also be occurring during the time period, such as changes in enforcement practices associated with marijuana offences. For example, Reuter, Hirschfield and Davies (2001) find that one-third of those arrested for marijuana possession in three major Maryland counties spend time in jail pre-trial, even though almost none receive a sentence involving incarceration. Thus there may be variations over time in the extent of pre-trial detention that affect perceived penalties even though not targeted at marijuana use.

Murphy (1986) conducted an analysis of FBI records and showed that 7 out of the 11 states that chose to decriminalize marijuana during the late 1970 s ranked in the lowest 21 states in per capita marijuana possession arrests before they enacted their decriminalization law. Two states, Mississippi and North Carolina, were among the top 23 states in per capita arrests before their policy change. Murphy's (1986) analysis of changes in arrest patterns before and after the reform took place suggests that the statutory change had little impact on arrest patterns for any of these states. But survey data from that period, examined below, suggests that youth perceived significantly lower penalties following the legal change, and this shift only occurred in those states changing their laws. We will present evidence that these perceptual differences across states have largely vanished, suggesting either that "decriminalization" and "non-decriminalization" states no longer differ in their actual enforcement patterns, or that citizens no longer perceive the difference - perhaps due to the lower salience of the change over time.

\section{WHAT DOES IT MEAN TO DECRIMINALIZE?}

Much of the confusion about decriminalization involves terminology. The term "decriminalization" is often seen by the public as a synonym for "legalization." But this is a mistake; decriminalization refers to penalties for marijuana possession, and does not imply any change in the legal status of (or sanctions against) marijuana sales. Also, "decriminalization" literally implies a removal in the criminal status of marijuana possession offences; however, many jurisdictions that are recognized as having decriminalized marijuana in fact merely reduce the penalties associated with possession of specified amounts. In many ways, the term marijuana "depenalization" is a more useful term for describing the diversity in liberalizing policies that have arose across and within countries (e.g., MacCoun and Reuter, 2001). Decriminalization, nonetheless, remains the more common term in policy debates.

DOI: $10.2202 / 1555-5879.1227$ 
Table 1: Recognized U.S. State Policies and Statutory Law as of January 2001

\begin{tabular}{|c|c|c|c|c|c|c|c|c|c|c|c|}
\hline & I & 1 & II & 1 & III & & I & 1 & II & 1 & III \\
\hline State & 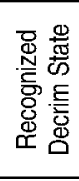 & $\begin{array}{l}1 \\
1 \\
1 \\
1 \\
1 \\
1 \\
1\end{array}$ & 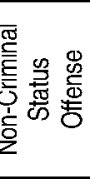 & 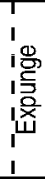 & 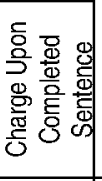 & State & 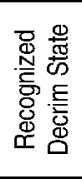 & $\begin{array}{l}1 \\
1 \\
1 \\
12 \\
12 \\
12 \\
1\end{array}$ & 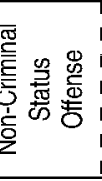 & $\begin{array}{l}1 \\
\text { 1: } \\
\text { 1: } \\
\text { ! } \\
\end{array}$ & 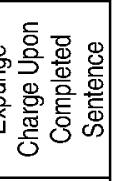 \\
\hline Alabama & & 1 & & $I$ & & Montana & & $I$ & & 1 & Yes \\
\hline Alaska & Yes & 1 & & I & & Nebraska & Yes & i & Yes & 1 & \\
\hline Arizona & Yes & 1 & & 1 & Yes & Nevada & & 1 & & 1 & \\
\hline Arkansas & & 1 & & 1 & & New Hampshire & & 1 & & 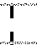 & \\
\hline California & Yes & 1 & & 1 & Yes & New Jersey & & 1 & Yes & 1 & \\
\hline Colorado & Yes & 1 & Yes & 1 & & New Mexico & & 1 & & 1 & Yes \\
\hline Connecticut & & 1 & Yes & 1 & & New York & Yes & 1 & Yes & 1 & \\
\hline Delaware & & $\mathrm{I}$ & & I & & North Carolina & Yes & 1 & & 1 & Yes \\
\hline Dist. Columbia & & 1 & & 1 & Yes & North Dakota & & 1 & & 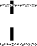 & Yes \\
\hline Florida & & 1 & & 1 & Yes & Ohio & Yes & I & & I & \\
\hline Georgia & & 1 & & i & & Oklahoma & & 1 & & 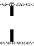 & Yes \\
\hline Hawaii & & 1 & & 1 & Yes & Oregon & Yes & 1 & Yes & I & \\
\hline Idaho & & 1 & & 1 & & Pennsylvania & & 1 & & 1 & Yes \\
\hline Illinois & & 1 & & 1 & & Rhode Island & & I & & I & Yes \\
\hline Indiana & & 1 & & 1 & Yes & South Carolina & & 1 & & I & Yes \\
\hline lowa & & 1 & & 1 & Yes & South Dakota & & 1 & & 1 & \\
\hline Kansas & & 1 & & I & Yes & Tennessee & & 1 & & I & Yes \\
\hline Kentucky & & 1 & & $i$ & Yes & Texas & & 1 & & 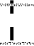 & \\
\hline Louisiana & & 1 & Yes & 1 & & Utah & & 1 & & I & Yes \\
\hline Maine & Yes & 1 & Yes & 1 & & Vermont & & 1 & Yes & 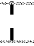 & Yes \\
\hline Maryland & & 1 & & 1 & & Virginia & & 1 & & 1 & \\
\hline Massachusetts & & 1 & Yes & 1 & & Washington & & 1 & & I & \\
\hline Michigan & & 1 & & 1 & & West Virginia & & 1 & Yes & 1 & Yes \\
\hline Minnesota & Yes & 1 & Yes & I & & Wisconsin & & 1 & Yes & I & \\
\hline Mississippi & Yes & 1 & Yes & 1 & Yes & Wyoming & & 1 & & 1 & \\
\hline Missouri & & 1 & & 1 & & Total \# of States & 12 & 1 & 14 & $I$ & 22 \\
\hline
\end{tabular}

In addition, progress in understanding the effects of marijuana laws has been hindered by an over-reliance on a crude dichotomous "decriminalization" indicator. Recent research demonstrates that this simple dichotomy is quite inadequate for uniquely identifying real differences in the criminal treatment of low-level marijuana offenders in the United States (Pacula et al., 2003, 2005). Table 1 summarizes statutory penalties in effect as of January 2001 for first time marijuana possession offenders caught in possession of small amounts of marijuana for all fifty states and the District of Columbia (Pacula et al., 2003). The correspondence between the "decriminalization" label and actual policies is quite variable. Seven states that had actually removed the criminal status of minor possession offenses 
(by 2001), were not formally recognized as decriminalized states. Five states that are widely recognized as having decriminalization statutes (Alaska, Arizona, California, North Carolina and Ohio) maintain the status of marijuana possession offences as a criminal charge. Some states allow a minor marijuana possession charge to be removed through a formal process called expungement. Many of the states that have expungement provisions are not known as decriminalized states, and only three of the five so-called decriminalized states retaining the criminal status of minor marijuana possession offences (Arizona, Califomia, and North Carolina) allow for the removal of the criminal charge upon completion of mandated punishment. It is also important to note that the decriminalization statutes do not remove criminal penalties for smoking marijuana in public, which has always constituted an important source of possession arrests.

In addition to this conceptual confusion, there is empirical uncertainty about the effects of marijuana laws on enforcement patterns. Pacula et al. (2005) examined the relationship between state marijuana statutes and actual enforcement during 1991-2000. They report a 264\% increase in marijuana possession arrests across all states, mostly occurring between 1991 and 1995. Between 1991 and 2000, there was a dramatic increase in variation across states, with the range increasing from about 30 arrests per 10,000 in 1991 to 110 arrests per 10,000 in 2000 . More importantly, by 2000 , states that had eliminated the criminal status of possession offences involving amounts of one ounce or less of marijuana did not have systematically lower arrests per capita than those states retaining the criminal status. More than half of the states that do not consider small marijuana possession offences a criminal offence still had per capita arrest rates greater than the national average and they still experienced a significant increase in arrests during the 1992-1995 time period. One interpretation is that these arrests do not reflect simple possession of marijuana but that many are the result of bargaining down from more serious offenses, such as marijuana distribution (see Caulkins and Chandler, 2006, for supporting evidence). But if these arrest rates do correspond to actual legal risks for marijuana possession, then it is

puzzling that recent studies find a consistent and statistically significant effect of the simple decriminalization dummy indicator on use even after controlling for enforcement (DeSimone and Farrelly, 2003; Pacula et al., 2003; Williams et al., 2004).

\section{DETERRENCE THEORY}

In theory, any deterrent effect of levels of marijuana sanctioning should be mediated by citizens' perceptions of sanction certainty and severity (see Caulkins

DOI: $10.2202 / 1555-5879.1227$ 
and MacCoun, 2003; MacCoun, 1993; Paternoster, 1987; Nagin, 1998). ${ }^{2}$ The "perceptual deterrence literature," which examines correlations between perceived sanction threats and self-reported behavior, suggests that the certainty of marijuana sanctioning has a modest deterrent effect, but that the effects of sanction severity are weak and unreliable (see Patemoster, 1987; MacCoun and Reuter, 2001). A recent meta-analysis (Pratt et al., 2006) estimated that the average correlation between perceived certainty and self-reported offending was -.171 ( $n=107$ estimates); the average correlation for perceived severity was only -.049 ( $n=47$ estimates).

Because decriminalization is a severity-based intervention, these results may explain those studies failing to detect reliable decriminalization effects. But as we have seen, those studies operationalized decriminalization using an imprecise and somewhat misleading dichotomous indicator. It is also possible that perceptual deterrence studies conducted within a criminalization regime understate the potential effects of decriminalization (MacCoun, 1993). The sanction certainty dimension may have important threshold effects. Sanctioning risks should have the greatest impact at the transition from a nonzero to a zero probability (Kahneman and Tversky, 1984). Also, the mere fact that an act is illicit (as marijuana possession remains under decriminalization) may influence behavior independently of the magnitude of the legal threat.

There may be similar discontinuities for the sanction severity dimension. Human judgment is notoriously susceptible to range and anchoring effects (Kahneman, 2003; for an application to sentencing judgments, see Enough and Mussweiler, 2001). Statutory maxima are an example of the kind of "worst case scenarios" that people tend to weight disproportionately (March and Shapira, 1987).

Whether decriminalization might have a larger than expected effect depends, in part, on whether citizens actually know something about their state's marijuana laws. Various lines of evidence suggest that citizens may have distorted or biased beliefs about sanctioning threats (see MacCoun, 1993, MacCoun and Reuter, 2001), but very little work has been done to empirically investigate whether this is true with respect to drug laws.

Relatively few studies have ever measured the accuracy of citizens' beliefs about legal sanctions. Early studies found that the general public tends to exaggerate the risks of arrest and punishment for many crimes (e.g., California Assembly Committee on Criminal Procedure, 1968; Erickson and Gibbs, 1978). The role of social networks and the mass media in shaping these perceptions is discussed elsewhere (Caulkins and MacCoun, 2003; MacCoun, 1993, 2001); here we limit our focus to the role of personal experience, for which there is more direct evidence. In accordance

2 We refer here to general deterrence; sanctions may also influence marijuana use through incapacitation (surely a negligible effect here), specific deterrence, price effects, availability effects, and stigma effects (see MacCoun, 1993; MacCoun and Reuter, 2001). 
with the availability heuristic (Tversky and Kahneman, 1974), those with personal experiences of arrests-as either offender, victim, or acquaintance-expect greater arrest risks than citizens without such experiences (Parker and Grasmick, 1979; Pratt et al., 2006). ${ }^{3}$ Those with personal experience in offending without sanctions perceive lower (and more accurate) sanctioning risks than the broad nonoffending public (Homey and Marshall, 1992; Parker and Grasmick, 1979; Patemoster, 1987). ${ }^{4}$ Unfortunately, most of these studies have examined relative risk on Likert-type attitude scales, rather than assessing actual knowledge of the criminal statutes.

Williams, Gibbs, and Erickson (1980) surveyed the beliefs of 2,400 Arizona adults about the penalties in their state for nineteen different crimes. They found moderate correlations between perceived and actual statutory maximums, but public beliefs were more strongly correlated with their attitudes toward appropriate sanctioning than with their knowledge of actual sanctioning. It is also possible that citizens' beliefs are shaped by legal tradition and fail to reflect more recent legal reform. Darley et al. (1996) examined public beliefs about sanctions for various crime scenarios, and found that citizens' intuitions better corresponded to the traditional common law than to the newer Model Penal Code in force in their state. The most comprehensive study of perceived sanction levels involved interviews in fifty-four urban counties (Kleck et al., 2005); in multivariate analyses, these perceptions were statistically unrelated to actual punishment levels in these counties.

We are aware of only one previous study examining the accuracy of citizen beliefs about their state marijuana laws, and it is quite dated. Using the Monitoring the Future survey of high school seniors, Johnston, O'Malley, and Bachman (1981) reported ratings for the Classes of 1976, 1977, 1978, 1979, and 1980 on the item "Which best describes the law IN YOUR STATE regarding marijuana? Possession in private of an ounce or less of marijuana (by an adult) is..." In Table 2, we summarize their results for the Classes of 1976 and 1980.

The most striking feature of Table 2 is the obvious difference in perceptions across states as a function of their legal status. In the early change states, only $14 \%$ (1976) to $16 \%$ (1980) of citizens believed marijuana possession carried a possible jail sentence. In the late change states the proportion of citizens holding this belief dropped precipitously, from $58 \%$ in 1976 to $18 \%$ by 1980 . In non-decriminalization states, roughly a third of citizens believed marijuana possession was punishable by jail: 39\% in 1976, 35\% in 1980 .

\footnotetext{
3 Anderson (2002) reports that a majority of his sample of prison and jail inmates thought it was unlikely (at the time of their offense) that they would be caught.

${ }^{4}$ MacCoun and Reuter (2001) estimated that marijuana users face a 3\% risk of arrest for a year of marijuana use. Caulkins and Sevigny (2006) estimated that marijuana users face a risk of about one hour in prison for every year of marijuana use. This latter calculation does not include time in local jail which may account for most of the incarceration served by marjuana possession arrestees.
}

DOI: $10.2202 / 1555-5879.1227$ 
Table 2. High School Seniors' Beliefs About Their State Marijuana Laws, by State Decriminalization Status (Johnston, O'Malley, and Bachman, 1981)

\begin{tabular}{|c|c|c|c|c|c|c|}
\hline & \multicolumn{2}{|c|}{$\begin{array}{l}\text { Early change states } \\
\text { (by April 1976) }\end{array}$} & \multicolumn{2}{|c|}{$\begin{array}{l}\text { Late change states } \\
\text { (by July 1977) }\end{array}$} & \multicolumn{2}{|c|}{ Other states } \\
\hline & 1976 & 1980 & 1976 & 1980 & 1976 & 1980 \\
\hline $\begin{array}{l}\text { A criminal offense, carrying a } \\
\text { possible jail sentence }\end{array}$ & 14.3 & 16.1 & 57.8 & 17.6 & 39.3 & 34.6 \\
\hline $\begin{array}{l}\text { A criminal offense, carrying a } \\
\text { possible fine, but no jail sentence }\end{array}$ & 14.3 & 16.4 & 15.6 & 23.1 & 16.1 & 22.9 \\
\hline $\begin{array}{l}\text { A non-criminal offense-like a } \\
\text { traffic ticket-carrying a small fine } \\
\text { and no criminal record at all }\end{array}$ & 33.1 & 20.6 & 1.5 & 18.7 & 4.2 & 5.2 \\
\hline $\begin{array}{l}\text { I don't know if the offense is } \\
\text { criminal, but I know it carries a fine }\end{array}$ & 15.9 & 10.8 & 2.2 & 16.5 & 9.5 & 5.8 \\
\hline Not a legal offense at all & 2.1 & 3.8 & 1.5 & 2.2 & 2.7 & 1.8 \\
\hline I just don't know & 20.5 & 32.2 & 21.5 & 22 & 28.4 & 29.8 \\
\hline $\mathrm{N}$ & 435 & 286 & 135 & 91 & 861 & 708 \\
\hline
\end{tabular}

The contrast to the actual statutory penalties described in Table 1 is quite striking. In the U.S. in the 1970s, it appears that many people were aware of their state marijuana laws. As Johnston and colleagues summarized their results: "In sum, we can say from the data just reviewed that there were substantial shifts in the perceptions of prevailing laws, but also that there were sizeable segments of the population in all three types of states who either did not know what the law was, or who very likely had an incorrect perception of what it was. In the decriminalized states roughly $10-20 \%$ of the respondents still believed that the penalty could include a jail sentence, while in non-decriminalized states roughly $30-40 \%$ incorrectly believed that a jail sentence was not an option."

Thus, it appears that in the 1970s, when most decriminalization reforms were still recent, citizens were moderately accurate in their knowledge of these laws. But as reviewed above, it is no longer certain that "decriminalization" as a label accurately distinguishes actual state differences in statutory maximum penalties for marijuana possession. In the remainder of this paper, we examine the accuracy of citizen perceptions using much more recent survey data, and we do so in a way that accounts for the complexity of state laws and for possible covariates that influence citizen perceptions. 
Perceived Marijuana Sanctions / 357

\section{DATA AND ANALYTIC STRATEGY}

\subsection{DATA SOURCE}

Starting in 2001 the National Survey on Drug Use or Health began inquiring about people's knowledge of penalties associated with possession of one ounce of marijuana. We pooled data from the 2001, 2002, and 2003 National Surveys on Drug Use and Health (NSDUH, formerly the National Household Survey on Drug Abuse). The Substance Abuse and Mental Health Services Administration (SAMHSA) conducts the NSDUH survey annually for the primary purpose of estimating the prevalence of illicit drug, alcohol, and tobacco use in the United States. The NSDUH sample is drawn from a clustered, multistage sampling design, resulting in a nationally representative sample of non-institutionalized civilians. There are roughly 600 adult respondents 18 and older in each state in each annual cross-section. Respondents are not followed over multiple years.

Interviews occur continuously throughout the calendar year and take roughly one hour to complete. To assure confidentiality, respondent names are not used; interviews are conducted in private; and sensitive questions about drug use are completed though audio-assisted computer interview technology (ACASI) where respondents key answers directly into a laptop computer in response to pre-recorded instructions. Further information on survey methodology is provided in the annual NSDUH findings report (SAMHSA, 2003). Several modifications to the survey design were initiated in 2002: a $\$ 30$ incentive was paid for completed interviews, a program to monitor and improve interviewer quality was implemented, and the name of the survey was changed from the National Household Survey on Drug Abuse to the NSDUH.

\subsection{ANALYTIC VARIABLES}

Our primary dependent measure for this analysis comes from a survey question inquiring about the respondent's knowledge of state penalties for possession of one ounce of marijuana. In each wave of the survey used here, respondents are asked, "What is the maximum legal penalty in (State of residence) for first offense possession of an ounce or less of marijuana for your own use?" Possible responses were (1) a fine, (2) probation, (3) community service, (4) possible prison sentence, (5) mandatory prison sentence, and (5) don't know. For the purposes of our analysis and to most closely match information on state penalties, we collapse responses into three categories: (1) fine, probation and/or community service; (2) don't know, and (3) possible or mandatory prison sentence. It is this categorical variable that is estimated using multinomial logistic regression.

Additional information about the individual is also captured from these surveys to control for individual factors that may be associated with use and/or

DOI: $10.2202 / 1555-5879.1227$ 
knowledge of the law. These include the following: gender (whether the respondent is male), race/ethnicity (white, Black, Hispanic, and other), age (18$25,26-34$, and older than 35 years), education (less than high school, some college, finished college), household composition (number of people in the household, number of children ages 17 and under), income $(<\$ 15 \mathrm{~K}, \$ 15 \mathrm{~K}$ $24 \mathrm{~K}, \$ 25 \mathrm{~K}-34 \mathrm{~K}, \$ 35 \mathrm{~K}-49 \mathrm{~K}, \$ 50 \mathrm{~K}-74 \mathrm{~K}$, or greater than $\$ 75 \mathrm{~K}$ ), participation in a government assistance program, religious beliefs (religious beliefs are important and attend services regularly), marital status (married, widowed, divorced/separated, and never married), employment status (full time, part time, unemployed and out of the labor force), school enrollment, and an indicator of whether the individual binge drank in the past 30 days. ${ }^{5}$ We also include as additional controls measures of the census region the person resides in and the size of the Metropolitan Statistical Area (large, small, or non-MSA).

Information on each state's laws regarding marijuana policy comes from two sources. First, information on decriminalization status comes from MacCoun and Reuter (2001). Second, information on statutory penalties associated with possession of one ounce of marijuana for first time offenders was collected by the MayaTech Corporation as part of the ImpacTeen project (see Pacula et al,, 2003 for more information about these data). The penalties represent laws in effect as of January $1^{\text {st }}$ of each year $(2001,2002$ and 2003) and include the minimum and maximum jail term, minimum and maximum fine, conditional discharge provisions, and expungement provisions for the lowest two quantity trigger amounts, which capture amounts of one ounce or less for all states. ${ }^{6}$ The conditional discharge variable reflects instances where compliance with the specified conditions leads to a dismissal of charges.

For the purposes of this analysis, we collapse information collected from these legal statutes into two alternative sets of policy variables. The first group represents the actual maximum penalties imposed by each law. We include in the regression three relevant dimensions that might influence perception of the laws: (a) the maximum fine statutorily imposed for possession of an ounce of marijuana, (b) the maximum jail time statutorily imposed, (c) the possibility of diversion to treatment, an education program or community service for first

\footnotetext{
5 Analyses were run without the measure of binge drinking and results were qualitatively similar to those presented here. We also considered models that included measures of perceived risk from regular use of marijuana. However, we are concemed that this variable also captures perceived legal risk, and hence may be endogenously determined. When the variable is included in the model, we find slightly larger policy effects in the direction shown in the paper here.

${ }^{6}$ Illinois is the only state in which the penalty for possession of an ounce of marijuana is captured in a higher quantity trigger (trigger number 3 ). In this one case we collected additional information so that we can reflect the penalties in place in all states for amounts involving one ounce of marijuana.
} 
time offenders, and (d) the presence of conditional discharge provisions for first time offenders (meaning that the criminal charge is erased upon successful completion of the sentence). These variables are not intended to be mutually exclusive, as many statutes do in fact include both a fine and jail time or fine and diversion. But, it is anticipated that individuals living in states with super high fines or long jail times would be more likely to identify these tough penalties as the "maximum penalty" than diversion to treatment, for example.

Given that very few individuals are likely to know precisely what the statutory penalties are, we also considered an alternative grouping of these actual penalties that emphasized what we expect to be the most salient feature of the statutory law: (a) those that have no maximum jail time mandated, (b) those that allow diversion for any offender, and (c) those where only a fine - no diversion and no jail time - is imposed. Here again the analytic variable are not mutually exclusive, as states that impose no maximum jail time (option a) might only impose a fine (option c) or might not. However, the goal is to see if any of these maximum statutory penalties have higher salience with individuals? perceptions of the laws for those living in these states.

To capture the risk of getting caught using marijuana, information on marijuana possession arrests are obtained from the Federal Bureau of Investigation's (FBI) Uniform Crime Report (UCR). The UCR system provides information on the number of crimes reported to the police in specific crime categories each year for every police jurisdiction in the United States. Arrests are reported by primary criminal offence. Data is collected on a monthly basis from approximately 17,000 law enforcement agencies and jurisdictions, although the crime and arrest data are not always complete from every agency. Each year, the Intra-university Consortium of Political and Social Research (ICPSR) generates county-level arrest estimates from the incomplete agency data by imputing for missing values and makes these data available to the public. We aggregate these data to construct an estimate of marijuana possession arrests per capita within each state and match this variable to our data based on state of residence of the respondent. ${ }^{7}$

\subsection{ANALYTIC SAMPLE AND ANALYTIC STRATEGY}

Our analysis focuses on 135,388 adults age 18 and older, among whom are 25,015 past-year and 14,739 past-month marijuana users (unweighted n's). We

7 Given the paucity of UCR data for Florida, Illinois, Kansas and Montana, no state estimate was calculated for these states and observations within these states are dropped when analyses include the marijuana enforcement variable. We also conducted runs using an alternative measure of enforcement: the percent of all drug possession arrests that are due to marijuana. Results are qualitatively similar to those presented here and are available upon request.

DOI: $10.2202 / 1555-5879.1227$ 
exclude individuals under 18 years of age because some states differ in their treatment of adults and juveniles and hence statutory penalties may not actually apply to all juvenile offenders. We also exclude a small percent $(<3 \%)$ of respondents with missing data on a few key control variables, including gender and religiosity. Imputed values, constructed by RTI for SAMHSA, on race/ethnicity, education, income, marital status and family composition were used to avoid excessive loss of observations.

We used a 'restricted use file' with geographic identifiers that enabled us to link state-level policy information and arrest data to respondents in the NSDUH based on state of residence. Because of the sensitive nature of these restricted data, all analyses were conducted on site at SAMHSA by SAMHSA staff to protect confidentiality.

Our dependent variable capturing knowledge of the state laws is a mutually exclusive, categorical variable, in that people respond that the maximum penalty is a fine (fine, probation, and/or community service), some jail time, or that they do not know. No state has a maximum fine not specified in the law, but the person is asked what they believe is the maximum penalty, so to some extent it is irrelevant that the state imposes multiple penalties, as the individual only identifies what they believe is the gravest penalty. Given that response categories are mutually exclusive (the respondent can only identify one), we estimate the model using a multinomial logistic framework given by:

$$
\operatorname{Prob}\left(Y_{i}=j\right)=e^{\left(\beta j^{\prime} X i+\gamma j^{\prime} Z i\right)} / \sum_{k=0}^{2} e^{\left(\beta k^{\prime} X i+\gamma k^{\prime} Z i\right)}
$$

where $Y_{i}$ represents the choice of respondent $i, j=$ the particular choice specified (jail, fine/probation/community service, and don't know), $X_{i}$ represents individual and locational (region, MSA, and year) characteristics that influence reported knowledge of the laws, while $Z_{i}$ represents the actual state policies operating within the state in which the respondent resides. For analytic purposes and ease of interpreting the coefficients, we have specified the three choices as follows:

$$
\begin{aligned}
k & =0 \text { if maximum penalty is some jail } \\
& =1 \text { if maximum penalty is a fine, probation or community service } \\
& =2 \text { if respondent says they don't know what the maximum penalty is. }
\end{aligned}
$$


Thus for all models, the omitted reference group is "some jail."8 All regression parameters, odds ratios, and standard errors were estimated using a methodology that accounts for the NSDUH's complex survey design using the survey data analysis procedures in STATA 8.0 (StataCorp, 2003). We calculated robust standard errors to reflect clustering resulting from the survey's complex, multistage design (see Office of Applied Studies, 2002). We also evaluated models adjusting for clustering at the state level, but report here the more conservative standard errors based on the survey's primary sampling units. Finally, we applied weights reflecting selection probabilities and non-response to all analyses in order to generalize to the U.S. population (SAMHSA, 2003).

\subsection{LIMITATIONS}

As with all self-reported studies of illicit behavior, there is a known risk of underreporting of drug use by respondents. Several changes to the NSDUH design were initiated in 2002 , including a $\$ 30$ incentive offered to respondents who provided a complete interview, a change in the name of the survey from the National Survey on Drug Abuse, and improved quality control procedures. These changes were associated with increased reporting of illicit drug use (SAMHSA, 2003). Results from the 2002 National Survey on Drug Use and Health: National Findings (Office of Applied Studies, 2002). In order for the methodology changes to bias our results, however, it would have to be the case that the methodology change affects the measured relationship between reported use and penalty perceptions after controlling for calendar year and covariates.

\footnotetext{
${ }^{8} \mathrm{~A}$ reviewer correctly pointed out that the multinomial logit model makes strong assumptions about the independence of irrelevant alternatives (IIA). A multinomial probit formulation sidesteps this concem by allowing correlated error terms, but is computationally very difficult for a large data set with more than four alternatives (Kennedy, 1998). Because we our analyses were performed on site at SAMHSA during a brief time period, we are unable to compare our results to a multinomial probit analysis, and we acknowledge the possibility that this issue may have produced some bias in our estimates. But other investigators have shown that multinomial probit estimates are not necessarily superior to multinomial logits (Dow and Endersby, 2004; Quinn et al., 1999), and violations of the IIA assumption are more plausible in consumer choice settings than in our context, where there is only one factually correct choice and where our list of altematives is more exhaustive than the typical citizen would encounter in any state.
}

DOI: $10.2202 / 1555-5879.1227$ 


\section{RESULTS}

\subsection{Simple Cross-Tabulations 9}

Table 3 presents aggregated state population level information on the proportion of people reporting particular penalties. The first column of Table 3 presents the fraction of the state population reporting a particular maximum penalty across all states, regardless of the state's actual penalties. On average we see that nearly one-third of the population do not know what the maximum penalty is for marijuana possession offences in their state and another third believe that possible or mandatory jail is the maximum offence. Note that $6 \%$ of the population reports that mandatory jail is the maximum offence for possession of an ounce of marijuana even though no U.S. state imposes a mandatory jail time for low-level marijuana possession offences.

We next categorized states based on whether they were recognized in the literature as having a decriminalization policy ("decrim") or not ("nondecrim"). Although we showed in Table 1 that these policies do not reflect actual differences in the criminal status of marijuana offences, it may be the case that the mere label that has been applied to these states for the past 25 years might generate a greater awareness of the state's actual penalties for those living within these states. If people living in decriminalized states were actually aware of this labeled policy (i.e., that a violation was not subject to criminal penalties), then we would expect them to be less likely to report jail as the maximum penalty, and more likely to report fines as the maximum penalty, than people living in non-decrim states. And indeed this is what we observe in Table 3. However, the actual magnitude of these differences is extremely modest and nearly $30 \%$ of people living in a so-called decriminalized state still report jail as the maximum penalty imposed.

The table also shows that community service was equally likely to be cited in decrim and non-decrim states, and probation was more likely to be named in non-decrim states. Note that diversion to probation or community service exists only as a judicial option in lieu of criminal sanctions, so it comes as no surprise that these are not cited more frequently by citizens in decrim states.

\footnotetext{
${ }^{9}$ This section is adapted from material in Pacula et al. (2005).
} 
Perceived Marijuana Sanctions / 363

Table 3: Reported Maximum Penalty for Possession of 1 oz. of Marijuana Aggregated State-Level Data from the $2001 \mathrm{NSDUH}$

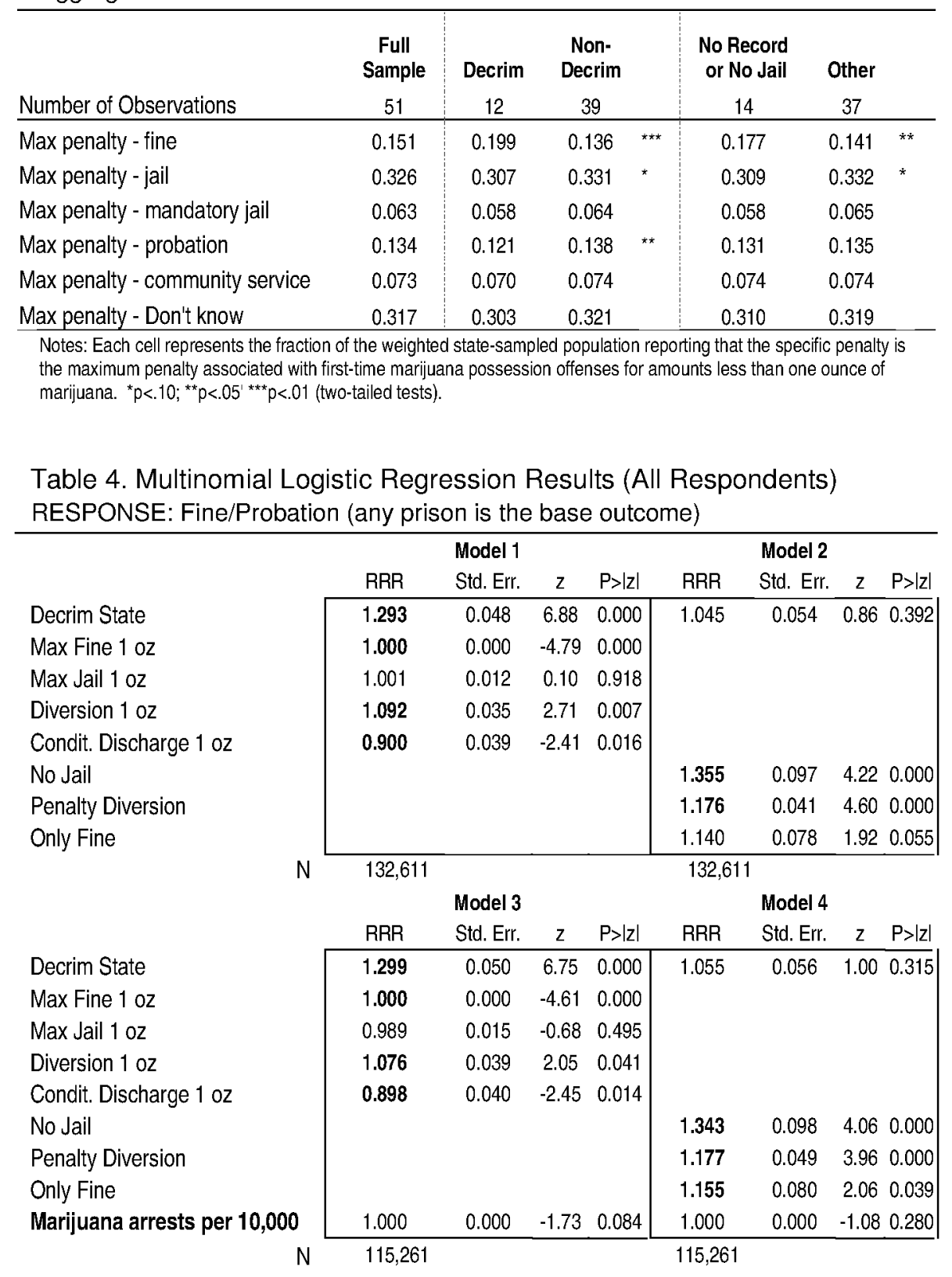

DOI: $10.2202 / 1555-5879.1227$ 
One explanation for this small difference in reported penalties is that we have misclassified people based on decriminalization status, as several other states have also eliminated jail time for possession offenses (Pacula et al., 2003). So, in the second part of Table 3, we show differences in the fraction of the state population reporting specific penalties for states in which the jail times have been removed as a penalty (either by a change in the criminal status or a reduction in penalties) and those that do not. Again we find that individuals living in states that have statutorily removed jail sentences as penalties for possession of up to an ounce of marijuana are statistically less likely to report jail as the maximum penalty and more likely to report fines as the maximum penalty. However, again we see that the actual difference in knowledge across states is small.

Interestingly, the "Don't Know" rates in Table 3 (30\% for decriminalization and $32 \%$ for non-decriminalization states) correspond relatively closely to the "Don't Know" rates in the 1976 and 1980 Monitoring the Future Survey data in Table 2 ( 20 to $32 \%$ ). There is no indication that citizens perceive themselves to be better informed in one period than in the other.

\subsection{MULTIVARIATE ANALYSES}

In Table 4 we report the results of a set of multivariate logit models which more precisely assess the association between state marijuana laws and the perception that marijuana possession is punishable by a fine or probation (henceforth, "lenient sanctioning") relative to mandatory/possible jail time. The reported coefficients are relative risk ratios. Each model included 42 control variables not presented in the tables, including gender, race, income category, household size, number of children $<17$ years of age, attendance at religious services, importance of religion, Census region ( 9 regions), age, marital status, educational attainment, employment status, school enrollment status, year dummies, and MSA size. All regressions were adjusted for sampling weights and for clustering at the county level.

In Model 1, we see that individuals living in so-called decrim states are $29 \%$ more likely to report that the maximum penalty is a fine or probation instead of possible jail time or prison than individuals living in non-decrim states. At first glance this suggests that people living in states with more lenient sanctions might actually be aware of them. However, the findings with respect to the actual penalties imposed cast some doubt on that conclusion. For example, individuals living in states with higher maximum fines or higher jail terms are just as likely to report fines and probation (rather than jail/prison) as the highest penalty for those individuals living in states with low statutory fines or jail terms.

Thus in Model 2, we examine an alternative set of three state indicators, finding somewhat strong effects. These alternative indicators provide more consistent 
evidence that individuals living in states with more lenient laws are more likely to report that the maximum penalty imposed for possession of an ounce of marijuana is a fine or probation instead of jail or prison. Although the decrim variable is no longer statistically significant, individuals who live in a state that do not impose jail as a maximum penalty for possession of marijuana are $36 \%$ more likely to report a fine or probation instead of jail or prison as the maximum penalty. Furthermore, individuals who live in states that enable diversion of offenders are $18 \%$ more likely to report fine or probation as the maximum penalty than jail or prison than those in states that do not statutorily allow for diversion. Similarly, individuals living in states where only a fine is imposed are $14 \%$ more likely to report fine/probation as the maximum penalty (instead of possible jail/prison) than those individuals living in states that impose other penalties, but these results are not statistically significant at conventional levels.

Models 3 and 4 replicate Models 1 and 2, but include measures for actual enforcement - operationalized as the number of marijuana possession arrests per 10,000 residents. We find no increased relative risk for reporting fine/probation over jail/prison for individuals living in states with higher marijuana per capita rates. The findings with respect to the other laws are nearly identical to those reported in Models 1 and 2.

In Table 5, we present an additional four models; in these analyses we limit the sample to those who report having used marijuana in the past year. Because we are interested here in the fact of their use rather than their amount of use (or other correlates of use), we control for the frequency of their past-year use in all of these models.

Model 5 suggests that past-year users are more aware of their state's decriminalization status than are citizens in general, as past year users living in decrim states are $72 \%$ more likely to report a fine or probation as the maximum penalty instead of jail or probation than past year users living in nondecrim states. The findings with respect to the actual maximum penalties, however, remain inconsistent, again possibly reflecting that it is particular aspects of these laws, not the actual laws themselves, that influence perception. In Model 6, we find that past year users living in decrim states are almost $20 \%$ more likely to report that the maximum penalty is a fine or probation rather than jail or prison than past year users in non-decrim states. And, we see that past-year users living in state with no maximum jail time imposed are $86 \%$ more likely to report that the maximum penalty is a fine/probation rather than jail/prison than past year users living in states with no maximum jail time. Similarly, past year users living in states that allow for diversion are $18 \%$ more likely to report a maximum penalty of fine/probation versus jail/prison than past year users living in states not allowing diversion.

DOI: $10.2202 / 1555-5879.1227$ 
Table 5. Multinomial Logistic Regression Results (Past-Year Users Only) RESPONSE: Fine/Probation (any prison is the base outcome)

\begin{tabular}{|c|c|c|c|c|c|c|c|c|}
\hline & \multicolumn{4}{|c|}{ Model 5} & \multicolumn{4}{|c|}{ Model 6} \\
\hline & RRR & Std.Err. & $z$ & $P>|z|$ & RRR & Std.Err. & $z$ & $P>|z|$ \\
\hline Decrim State & 1.723 & 0.125 & 7.50 & 0.000 & 1.196 & 0.106 & 2.02 & 0.043 \\
\hline Max Fine $10 z$ & 1.000 & 0.000 & -2.37 & 0.018 & & & & \\
\hline Max Jail $1 \mathrm{oz}$ & 0.977 & 0.026 & -0.88 & 0.379 & & & & \\
\hline Diversion $10 z$ & 1.218 & 0.082 & 2.94 & 0.003 & & & & \\
\hline Condit. Discharge 1 oz & 0.965 & 0.092 & -0.37 & 0.709 & & & & \\
\hline No Jail & & & & & 1.862 & 0.251 & 4.60 & 0.000 \\
\hline Penalty Diversion & & & & & 1.181 & 0.088 & 2.22 & 0.026 \\
\hline Only Fine & & & & & 0.936 & 0.131 & -0.47 & 0.640 \\
\hline \multirow[t]{4}{*}{ Frequency of MJ use past yr } & 1.001 & 0.000 & 4.45 & 0.000 & 1.001 & 0.000 & 4.57 & 0.000 \\
\hline & $N 24,561$ & & & & 24,561 & & & \\
\hline & \multicolumn{4}{|c|}{ Model 7} & \multicolumn{4}{|c|}{ Model 8} \\
\hline & RRR & Std.Err. & $z$ & $P>|z|$ & RRR & Std.Err. & Z & $P>|z|$ \\
\hline Decrim State & 1.745 & 0.131 & 7.43 & 0.000 & 1.134 & 0.105 & 1.37 & 0.172 \\
\hline Max Fine $1 \mathrm{oz}$ & 1.000 & 0.000 & -2.36 & 0.018 & & & & \\
\hline Max Jail $1 \mathrm{oz}$ & 1.004 & 0.032 & 0.12 & 0.908 & & & & \\
\hline Diversion $1 \mathrm{oz}$ & 1.222 & 0.092 & 2.65 & 0.008 & & & & \\
\hline Condit. Discharge 1 oz & 0.929 & 0.091 & -0.75 & 0.450 & & & & \\
\hline No Jail & & & & & 1.968 & 0.268 & 4.97 & 0.000 \\
\hline Penalty Diversion & & & & & 1.231 & 0.102 & 2.50 & 0.012 \\
\hline Only Fine & & & & & 0.988 & 0.141 & -0.09 & 0.931 \\
\hline Frequency of MJ use past yr & 1.001 & 0.000 & 4.86 & 0.000 & 1.001 & 0.000 & 4.98 & 0.000 \\
\hline \multirow[t]{2}{*}{ Marijuana arrests per 10,000} & 1.000 & 0.001 & 0.00 & 0.997 & 1.001 & 0.001 & 1.05 & 0.292 \\
\hline & \multicolumn{4}{|l|}{$N 21,388$} & 21,388 & & & \\
\hline
\end{tabular}

Models 7 and 8 show that these beliefs are not influenced by including enforcement risk (marijuana arrests per 10,000 citizens) in the analysis. In additional analyses (not shown), we found the same effect of the decriminalization indicator (relative risk ratio $=1.3$ ) when all the other marijuana policy indicators were excluded.

\section{DISCUSSION}

Our study finds significant associations between the maximum penalty specified in state marijuana laws and citizens' perceived maximum penalties. But the associations are very small in magnitude. Citizens in decriminalization states are only about 29 percent more likely to believe the maximum penalty for possessing an ounce of marijuana is a fine or probation rather than jail 
(relative odds ratio $=1.29)$. About a third of citizens in each type of state believe the maximum penalty is a jail sentence. People are not oblivious to their marijuana laws, but the average citizen's awareness is pretty tenuous. This fact, combined with prior evidence for only weak effects of perceived sanction severity on offending (Pratt et al., 2006), goes a long way toward clarifying why decriminalization effects are fairly weak and inconsistent.

As might be expected, experienced users showed a greater awareness of their state marijuana laws. Past-year users were 72 percent more likely (relative odds ratio $=1.72$ ) to believe the maximum penalty was a fine rather than jail when they lived in a decriminalization state than when they did not. This suggests that decriminalization may have greater potential to influence how much experienced users consume (in economic jargon, the "intensive margin") than it does to influence whether people use at all (the "extensive margin").

Unfortunately, most studies of decriminalization have focused exclusively on its effects on prevalence. This is perhaps explainable by the paucity of reliable measures of quantity or frequency of consumption. But it is also consistent with the dominant question in the policy debate (MacCoun and Reuter, 2001): "Would decriminalization encourage more people to use marijuana?" An alternative framing - "Would decriminalization increase total consumption of marijuana?" - would be consistent with the way demand is conceived in conventional microeconomic analysis, and arguably the better way to assess the public health and safety impacts of drug laws.

There is a need for caution in generalizing from the effects of state marijuana laws to any effect of a comparable change at the federal level. States that have depenalized marijuana remain subject to the more stringent federal prohibition. In practice, this means more for traffickers than for ordinary users. But in a state like California, citizens have repeatedly seen news coverage of federal crackdowns on marijuana (e.g., raids on medical marijuana buying clubs). This inconsistency may cloud citizens' understanding of their state laws. Federal decriminalization (rather than legalization) of marijuana might have modest legal consequences but a more profound perceptual effect.

Various methodological differences make it difficult to directly compare our results to those of the 1980 Monitoring the Future data (Table 2). Still, it is intriguing that students in the late 1970s seemed so cognizant of their state's legal status. Of course, that was the peak period for student marijuana use, and we have seen that users track their laws better than do non-users. But it is also possible that the publicity surrounding a change in law has a stronger effect on perceptions than the law's actual implementation. In the 1970s, the initial decision to decriminalize marijuana was a matter of active public debate. MacCoun and Reuter (2001, Table 3.2; also see MacCoun et al., 1993) report that in the 1970s, 22 out of

DOI: $10.2202 / 1555-5879.1227$ 
22 New York Times op-ed essays on drug legalization or drug decriminalization mentioned marijuana; only 15 out of 37 did so in the 1990 s. We believe that recent changes in these penalties have received far less publicity; only those interested in obtaining this information search it out. There may also have been erosion over time in knowledge of what may have been, in the 1970s, a real policy change. Indeed, research in other policy areas has shown that the impact of a policy is usually seen within a one- to three-year period following the policy's adoption/effectiveness date (MacCoun, 1993; Ross, 1976). Given that many of the depenalization policies examined here occurred well before 2001, time may have decayed people's knowledge or awareness of the laws.

Our understanding of the effects of marijuana decriminalization is far from perfect. Early studies failed to find an effect of decriminalization in an era in which citizens clearly recognized a difference in policies across states. Yet some recent studies have appeared to find a decriminalization effect in a more recent era, when the average citizen can just barely detect a difference in state laws. Of course, some citizens might use regardless of state laws, and others would never use marijuana (they are "inframarginal"), so what matters is knowledge among those at the margin. But three lines of evidence - the direct estimates of the effects of US and international marijuana laws, the weak severity effect in the perceptual deterrence literature, and the limits of citizen knowledge of penalties - leads us to believe that marijuana decriminalization has far more modest effects than opponents anticipate.

\section{REFERENCES}

Anderson, D.A. 2002. "The Deterrence Hypothesis and Picking Pockets at the Pickpocket's Hanging," 4 American Law and Economics Review 295-313.

California Assembly Committee on Criminal Procedure. 1968. Deterrent Effects of Cniminal Sanctions. Sacramento, CA: California Assembly.

Cameron, L., and J. Williams. 2001. "Cannabis, Alcohol and Cigarettes: Substitutes or Complements?" 77 Economic Record 19-34.

Caulkins, J.P., and S. Chandler. 2006. "Long-Run Trends in Incarceration of Drug Offenders in the U.S.," 52 Cnime and Delinquency 619-641.

and R.J. MacCoun. 2003. "Limited Rationality and the Limits of Supply Reduction," 33 Journal of Drug Issues 433-464. and E.L. Sevigny. 2006. "How Many People Does the US Imprison for Drug Use, and Who are They?" 32(3) Contemporary Drug Problems 405-428.

Darley, J.M., C.A. Sanderson, and P.S. LaMantia. 1996. "Community Standards for Defining Attempt: Inconsistencies with the Model Penal Code," 39 American Behavioral Scientist 405-420. 
DeSimone, J., and M.C. Farrelly. 2003. "Price and Enforcement Effects on Cocaine and Cannabis Demand," 41 Economic Inquiry 98-115.

DiNardo, J., and T. Lemieux. 2001. "Alcohol, Marjuana, and American Youth: The Unintended Effects of Government Regulation," 20 Joumal of Health Economics 991-1010.

Donnelly, N., W. Hall, and P. Christie. 1995. "The Effects of Partial Decriminalisation on Cannabis Use in South Australia 1985-1993," 19 Australian Joumal of Public Health 281-87.

Dow, J.K, and J.W. Endersby. 2004. "Multinomial Probit and Multinomial Logit: A Comparison of Choice Models for Voting Research," 23 Electoral Studies 107-122.

Enough, B., and T. Mussweiler. 2001. "Sentencing under Uncertainty: Anchoring Effects in the Courtroom," 31 Journal of Applied Social Psychology 1535-1551.

Erickson, M.L., and J.P. Gibbs. 1978. "Objective and Perceptual Properties of Legal Punishment and the Deterrence Doctrine," 25 Social Problems 253-264.

Federal Bureau of Investigation. 2001. Cnme in the United States 2000, Uniform Cnime Reports. Washington, DC: U.S. Department of Justice.

Hall, W., and R.L. Pacula. 2003. Cannabis Use and Dependence: Public Health and Public Policy. Melbourne, Australia: Cambridge University Press.

Horney, J., and I.H. Marshall. 1992. "Risk Perceptions Among Serious Offenders: The Role of Crime and Punishment," 30 Criminology 575-594.

Johnston, L.D., P.M. O'Malley, and J.G. Bachman. 1981. Cannabis Decriminaliqation: The Impact on Youth 1975-1980. Monitoring the Future Occasional Paper no. 13. Ann Arbor, Michigan: Institute for Social Research, University of Michigan.

Kahneman, D. 2003. "Maps of Bounded Rationality," in Tore Frängsmyr, ed. The Nobel Prizes 2002. Stockholm: Nobel Foundation. and A. Tversky. 1984. "Choices, Values, and Frames," 39 American Psychologist 341-350.

Kennedy, P. 1998. A Guide to Econometrics, $4^{\text {th }}$ ed. MIT Press.

Kessler, D., and S.D. Levitt. 1999. "Using Sentence Enhancements to Distinguish Between Deterrence and Incapacitation," 42 Joumal of Law and Economics 343-363.

Kleck, G., B. Sever, S. Li, and M. Gertz. 2005. "The Missing Link in General Deterrence Research," 43 Cniminology 623-660.

March, J.G., and Z. Shapira. 1987. "Managerial Perspectives on Risk and Risk Taking," 33 Management Science 1404-1418.

MacCoun, R.J. 1993. "Drugs and the Law: A Psychological Analysis of Drug Prohibition," 113 Psychological Bulletin 497-512.

2001. "Public Opinion about Legal Issues," International Encyclopedia of the Social and Bebavioral Sciences. Amsterdam: Elsevier. , J.P. Kahan, J. Gillespie, and J. Rhee. 1993. "A Content Analysis of the Drug Legalization Debate," 23 Journal of Drug Issues 615-629. and P. Reuter. 1997. "Interpreting Dutch Cannabis Policy: Reasoning by Analogy in the Legalization Debate," 278 Sience 47-52. and 2001. Drug War Heresies: Learning from Other Vices, Times and Places. Cambridge: Cambridge University Press.

DOI: $10.2202 / 1555-5879.1227$ 
McGeorge, J., and C.K. Aitken. 1997. "Effects of Cannabis Decriminalization in the Australian Capital Territory on University Students' Patterns of Use," 27 Journal of Drug Issues 785-793.

Model, K. 1993. "The Effect of Marijuana Decriminalisation on Hospital Emergency Room Drug Episodes: 1975-1978," 88 Joumal of the American Statistical Association 737-47.

Murphy, S.E. 1986. Marijuana Decriminalization: The Unfinished Reform. Dissertation, University of Missouri.

Nagin, D. 1998. "Criminal Deterrence Research at the Outset of the Twenty-First Century," 23 Crime and Justice: A Review of Research 1-42.

Office of Applied Studies. 2002, "National Survey on Drug Use and Health: National Findings," NHSDA Series H-22, DHHS Publication No. SMA 03-3836. Rockville, MD: U.S. Department of Health and Human Services.

Pacula, R.L. 1998. "Does Increasing the Beer Tax Reduce Marijuana Consumption?" 17 Joumal of Health Economics 557-586.

J.F. Chriqui, and J. King. 2003. Decriminaliation in the United States: What Does it Mean? National Bureau of Economic Research Working Paper \# 9690. , R.J. MacCoun, P. Reuter, J.F. Chriqui, B. Kilmer, K. Harris, L. Paoli, and C. Schaefer. 2005. "What Does it Mean to Decriminalize Cannabis? A CrossNational Empirical Examination," in B. Lindgren and M. Grossman, eds. Advances in Health Economics and Health Semices Research, vol. 16: Substance Use: Individual Behavior, Social Interactions, Markets and Politics. Elsevier Press.

Parker, J., and H. Grasmick. 1979. "The Effect of Actual Crimes and Arrests on People's Perceptions of the Certainty of Arrest: An Exploratory Study of an Untested Proposition in Deterrence Theory," 17 Cniminology 366-379.

Patemoster, R. 1987. "The Deterrent Effect of the Perceived Certainty and Severity of Punishment: A Review of the Evidence and Issues," 4 Justice Quarterly 173-217.

Pratt, T.C., F.T. Cullen, K.R. Blevins, L.E. Daigle, and T.D. Madensen. 2006. "The Empirical Status of Deterrence Theory: A Meta-Analysis," in F.T. Cullen et al., eds. Taking Stock: The Status of Criminological Theory: Advances in Criminological Theory, Vol. 15, 367-395. New Brunswick, NJ: Transaction.

Quinn, K.M., A.D. Martin, and A.B. Whitford. 1999. "Voter Choice in Multi-Party Democracies: A Test of Competing Theories and Models," 43 Amenican Journal of Political Science 1231-1247.

Reuter, P., P. Hirschfield, and C. Davies. 2001. Assessing the Crackdown on Marijuana in Maryland," unpublished manuscript, University of Maryland.

Reyda, V.F., and F. Farley. 2006. "Risk and Rationality in Adolescent Decision Making," 7 Psychological Science in the Public Interest 1-44.

Ross, H.L. 1976. "The Neutralization of Severe Penalties: Some Traffic Law Studies," 10 Law and Society Review 403-413.

Saffer, H., and F.J. Chaloupka. 1999. "The Demand for Illicit Drugs," 37 Economic Inquiry 401-411.

Single, E. 1989. "The Impact of Marijuana Decriminalization: An Update," 10 Journal of Public Health Policy 456-466. 
Substance Abuse and Mental Health Services Administration (SAMHSA). 2003. Results from the 2002 National Survey on Drug Use and Health: National Findings. NHSDA, Series H-22. DHHS Publication No. SMA 03-3836. Rockville, MD.

StataCorp. 2003. Sumvey Data, Release 8.0. College Station, TX: Stata Corporation.

Terry-McElrath, Y.M., and D.C. McBride. 2004. "Local Implementation of Drug Policy and Access to Treatment Services," 50 Crime and Delinquency 60-67.

Thies, C.F., and CA. Register. 1993. "Decriminalization of Marijuana and the Demand for Alcohol, Marijuana and Cocaine," 30 Social Science Journal 385-399.

Thomas, C. 1999. "Cannabis Arrests and Incarceration in the United States," 7 FAS Drug Policy Analysis Bulletin 5-7.

Tversky, A., and D. Kahneman. 1974. "Judgment Under Uncertainty: Heuristics and Biases," 185 Science 1124-1131.

van het Loo, M., I. van Beusekom, and J.P. Kahan. 2002. "Decriminalization of Drug Use in Portugal: The Development of a Policy," 582 Annals of the American Academy of Political and Social Science 49-63.

Williams, J. 2003. "The Effects of Price and Policies on Cannabis Consumption," 13 Health Economics 123-137.

, R.L. Pacula, F.J. Chaloupka, and H. Wechsler. 2004. "Alcohol and Cannabis Use among College Students: Economic Complements or Substitutes?" 13 Health Economics 825-843.

Williams, K.R., J.P. Gibbs, and M.L. Erickson. 1980. "Public Knowledge of Statutory Penalties: The Extent and Basis of Accurate Perception," 23 Pacific Sociological Review 105-128.

DOI: $10.2202 / 1555-5879.1227$ 
